\title{
Review of Whispers from The Bush: The Workplace Sexual Harassment of Australian Rural Women by Skye Saunders
}

Federation Press, 2015, 220 pages

ISBN: 9781760020385

\section{Review by Walter S. DeKeseredy West Virginia University, Morgantown, WV, USA \\ Walter.dekesseredy@mail.wvu.edu}

It was not until the publication of Gagne's (1992) feminist ethnographic work in Appalachia that the international sociological and criminological communities started to develop rich social scientific knowledge about woman abuse in rural communities. Shortly after came Websdale's (1998) seminal Rural Woman Battering and the Justice System: An Ethnography. As we progress toward the end of this decade, there is now a significantly larger academic literature on male physical and sexual violence against women in rural places, and there is conclusive evidence showing that rural women in both the Global North and Global South are more likely to be victimized by these behaviors than are their urban and suburban counterparts (DeKeseredy \& Hall-Sanchez, 2018; DeKeseredy, Hall-Sanchez, Dragiewicz, \& Rennison, 2016). Still, there is much that rural criminologists and sociologists do not know about some highly injurious male patriarchal practices that exist on what British radical feminist Liz Kelly $(1987,1988)$ refers to as the "continuum of sexual violence," ranging from nonphysical acts such as obscene phone calls to physical acts like rape or beating someone up. Although the idea of the continuum is often used to portray moving from the least serious to the most serious, to feminist scholars like Kelly (1988) and to many adult female survivors of male abuse, all these behaviors are serious and have a "basic common character" (p. 76). Since none is automatically considered more hurtful than another and that they all are types of "abuse, intimidation, coercion, intrusion, threat, and force" used to control and dominate women (Kelly, 1988, p. 76), they recommend that researchers not create a hierarchy of abuse or violence.

Skye Saunders, author of Whispers From The Bush, also views sexual violence on a continuum. Following in Kelly's 30-year-old footsteps, she supports Kelly's (2012) claim that her pioneering conceptual work continues to "stand the test of time" (p. xvii). More importantly, to the best of my knowledge, Saunders has written the first social scientific book on sexual harassment in rural workplaces and this behavior is certainly part of the continuum of sexual violence. Her main argument is that "there is a cultural epidemic of sexual harassment in rural Australian workplaces that must be addressed by supporting rural workplaces in realizing relevant provisions of the Sex Discrimination Act 1984 (Cth) and by effectuating broader cultural change" (p. 2). Empirically supporting her claim are data derived from 84 interviews with rural female employees, 23 interviews with rural employers (of either sex), and a statistical and analytical analysis of 68 adjudicated workplace sexual harassment cases heard throughout 
Australia between 2005 and 2010. Eleven of these cases were categorized as rural and 57 were labelled urban.

Saunders' interpretation and explanation of her findings draw from gender and legal theory, historical literature, and socio-economic work on the Australian bush, which is, in her words, "a setting separate and culturally distinct from the metropolitan centers" (p. 3). As well, Saunders' fully recognizes that defining the concept "rural" is subject to much debate, but, as she correctly notes, "there is a need for a clear and functional working definition" (p. 3). Her definition of rural is "an area at least 30 kilometers outside of outer boundaries of an 'urban' center, with relative dispersal of residence on relatively large parcels of land with generally less than 50,000 people" (p. 14). Her definition of "sexual harassment" is that of the Australian Human Rights Commission: "any unwanted or unwelcome sexual behavior, which makes a person feel offended, humiliated or intimidated" (p. 6).

Saunders' study has many strengths, one of which is her use of behaviorally specific questions about sexual harassment. Rather than ask respondents if they have experienced or witnessed "sexual harassment," she provided them with a list of behaviors ranging from "being subject to jokes in the workplace which have a rude, suggestive or distasteful punchline" to "unwanted physical touching or indecent exposure by someone with whom you work with" or "other types of sexual assault by someone you work with" (p. 24). The important point to consider here is that unless women clearly label hurtful behaviors as "sexual harassment" in their minds, they tend not to report them in a survey that uses narrow, legalistic language. If you tell someone that you are studying behaviors that are violations of legal norms, the typical person will only answer "yes" if they have in mind that an act of sexual harassment is such a violation. The problem is that in dealing with sexual harassment, including its physical variants, many women who experience what the law defines as sexual harassment do not label their victimization this way or sometimes even as a form of victimization. Saunders is keenly aware of the problems with using legal language and her interviewing strategy is consistent with those used by a large international group of violence against women researchers.

Another strength is her mixed-method approach, which resulted in the collection of pathbreaking data. It is beyond the scope of this review to summarize all her findings and accordingly only a few of the most salient ones are listed below:

- $73 \%$ of the employees interviewed reported experiencing one or more types of sexual harassment.

- $70 \%$ of the employees said they witnessed sexual harassment. 
- Those holding agricultural/horticultural jobs were the most likely to be victimized and to have witnessed sexual harassment, followed by women in mining occupations.

- The lower the proportion of women in the workplace, the higher the frequency of sexual harassment.

- Two-thirds of the employees blamed female targets of sexual harassment for their victimization.

- $83 \%$ of 18 employer respondents believed that women contribute to their sexual harassment.

- Male bonding or "mateship" is a powerful determinant of sexual harassment.

What is to be done about sexual harassment in the Australian bush? Saunders' answers to this question can inform policies in other countries, such as Canada and the United States. Further, though she does not explicitly state this, her solutions are informed by left realism, a school of thought that is one of at least 10 variants of critical criminology. If there are different definitions of rural, the same can be said about critical criminology. Here, it refers to a perspective that views the unequal class, race/ethnic, and gender relations the major sources of crime and determinants of social control.

One thing that differentiates left realism from many other types of critical criminology is the constant attention to progressive, short-term, anti-crime policies and practices. Eliminating broader forms of inequality, such as patriarchy is the ultimate goal, but left realists know that this radical change is not coming soon and hence it is necessary to chip away at the broader economic, social, political, and cultural forces that contribute to sexual harassment and other damaging symptoms of structured social inequality. Saunders knows this too and she offers recommendations that fall under these headings:

- "Changing Minds and Hearts": Re-inventing Male Behavior in the Rural Space;

- "Getting Bossy": Educating and Empowering Employers and Senior Managers to Recognize and Eliminate Workplace Sexual Harassment

- "Beyond Bitchy": Empowering Rural Women to Reject All Forms of Sexual Harassment and Support One Another (P. 153).

Male peer support theorists and members of the feminist men's movement will find Saunders' "Changing Minds and Hearts" initiatives to be especially useful. Male peer support 
theorists focus on men's attachments to male peers and the resources they provide that perpetuate and legitimate woman abuse. The feminist men's movement works tirelessly to end violence against women and other symptoms of patriarchy, and feminist men's groups are scattered throughout many countries, including Canada, the United States, the United Kingdom, and in Australia where Saunders is based. Two key examples of Saunders' strategies for changing men are identifying male "champions of change" who are willing to serve as role models for other men and using multi-media to convey the pain and suffering caused by sexual harassment.

Saunders makes explicit the limitations of her research, including the inability to generalize her results to all rural Australian workplaces and the use of a self-selected sample. Nonetheless, empirical work on rural workplace sexual harassment must start somewhere and Saunders should be commended for leading the charge. Undoubtedly, as she puts it, her book is "not the end of the story" (p. 175). She does suggest several directions for new research, but the section on potential new avenues of inquiry is rather brief and will leave readers wanting more.

If, as Saunders observes, sexual harassment is deeply entrenched in rural Australian workplaces, why does she use the term "epidemic." She contends that this word captures "the sense of sexual harassment as a debilitating condition (as with a disease) that has grown and spread to the point of excessive prevalence within particular communities" (p. 2). Actually, since she also states that sexual harassment is accepted as a "cultural norm," the concept of epidemic is out of place in her book. To health officials, an epidemic is a disease that devastates a population before eventually subsiding. Therefore, if sexual harassment in rural Australian workplaces is a disease, then it is in its endemic phase, possibly to be compared to opioid use in rural West Virginia. Perhaps, then, in her future work, Saunders should replace the term "cultural epidemic" with "culturally endemic."

This is a relatively minor criticism and does not, in any way, diminish the theoretically and empirically sophisticated nature of Saunders' offering. Her contribution is timely, much-needed, and policy relevant. It will also speak to readers on many levels, as it did to me. Most of the pages of my copy are marked with ink and many pages are dog-eared. As my dear friend and colleague Claire Renzetti (1997) notes, "From my experience as a teacher, researcher, editor, and activist, this is usually the sign of a very good book - good not only because it makes an interesting read but, more important, because it is 'useful'" (p. vii). I have certainly benefited from reading Whispers From The Bush and it will definitely serve as a catalyst for progressive change. 


\section{REFERENCES}

DeKeseredy, W. S., \& Hall-Sanchez, A. (2018). Male violence against women in the global south: What we know and what we don't know. In K. Carrington, R. Hogg, J. Scott, \& M. Sozzo (Eds.), The Palgrave handbook of criminology and the global south (pp. 883-900). Palgrave Macmillan. https://doi.org/10.1007/978-3-319-65021-0_42

DeKeseredy, W. S., Hall-Sanchez, A., Dragiewicz, M., \& Rennison, C. M. (2016). Intimate violence against women in rural communities. In J. F. Donnermeyer (Eds.), Routledge international handbook of rural criminology (pp. 171-179). Routledge. https://doi.org/10.4324/9781315755885-20

Gagne, P. L. (1992). Appalachian women: Violence and social control. Journal of Contemporary Ethnography, 20, 387-415. https://doi.org/10.1177/089124192020004001

Kelly, L. (1987). The continuum of sexual violence. In J. Hanmer \& M. Maynard (Eds.), Women, violence and social control (pp. 46-60). Humanities Press International. https://doi.org/10.1007/978-1-349-18592-4_4

Kelly, L. (1988). Surviving sexual violence. Polity Press.

Kelly, L. (2012). Standing the test of time?: Reflections on the concept of the continuum of sexual violence. In J. M. Brown \& S. L. Walklate (Eds.), Handbook on sexual violence (pp. xvii-xxiv). Routledge.

Renzetti, C. M. (1997). Foreword to M. D. Schwartz and W. S. DeKeseredy's Sexual assault on the college campus: The role of male peer support (pp. vii-xiii). Sage.

Websdale, N. (1998). Rural woman battering and the justice system: An ethnography. Sage. 